Editorial

\title{
Wine Traceability
}

\author{
Maria Carla Cravero
}

CREA Council for Agricultural Research and Economics, Research Centre for Viticulture and Enology, Via Pietro Micca 35, 14100 Asti, Italy; mariacarla.cravero@crea.gov.it

Received: 28 August 2019; Accepted: 29 September 2019; Published: 9 October 2019

check for updates

This Special Issue concerns wine traceability, a central theme in the current world market where consumers are increasingly demanding the quality and origin of food and drink.

The wine production chain and wine composition are generally controlled by different laws (International Organization of Vine and Wine (OIV), European union (EU) and national governments) and need specific documentation. Nevertheless, wine production is subject to fraud. As a consequence, the improvement of the methods applied to verify the origin and the quality of wines is really important to protect wine consumers and producers.

In this book eight different papers—six research papers and two reviews—address the topic from different points of view.

The first review [1] regards the latest trends in the polyphenol fingerprinting of red wines in association with their evolution during winemaking and storage. Polyphenols profiles are important to characterize grapes and wines, in particular color and sensory parameters, but also nutritional quality. The authors cite the literature on the characterization of the polyphenolic compounds from grapes and wines, polyphenol fingerprinting and analysis in red wines. Moreover, they also consider the current research on the factors affecting polyphenol content and distribution in wines.

The other review [2] presents several strategies to ensure the authenticity of wines, identifying new technological methods that can be employed in wine traceability. The authors emphasize an integrated approach to verify the origin of wine. In the paper we found an overview of the literature on analytical techniques for tracing the geographic provenance of wines. Moreover, the authors focus their interest on DNA fingerprinting for varietal identification and they show the pros and cons of DNA-based techniques applied to wine authentication.

The research papers propose different chemical instrumental analysis together with multi-variate statistical tools as methodologies to verify the origin of a wine. A group of Brazilian researchers [3] proposed a method based on data mining and predictive analysis to classify Brazilian and Uruguayan Tannat wines. In particular, they used the support vector machine (SVM) classification algorithm with the radial basis kernel function and the F-score feature selection method. The variables analyzed in the wines were color CIELAB parameters), total polyphenols, total anthocyanins, antioxidant activity by oxygen radical absorbance capacity (ORAC) and free radical scavenging activity (DPPH), and individual anthocyanins. The authors conclude that given the use of at least one anthocyanin (peonidin-3-glucoside) and DPPH, the Tannat wines can be classified with $94.64 \%$ accuracy and Matthew's correlation coefficient (MCC) of 0.90.

A research paper from Portugal [4] studied elemental composition with the aim of discriminating wines according to geographical origin, considering the effects of soil, winemaking process and vintage. The elemental composition of soils, grapes, musts and wines was determined by using inductively coupled plasma mass spectrometry (ICP-MS) followed by multivariate statistical analysis. The study evidenced that the mineral composition pattern is transferred through the soil-wine system, and differences observed for soils are reflected in grape musts and wines, but not for all elements. Li, Mn, Sr and rare-earth elements discriminated wines according to vineyard. Results suggest that winemaking 
processes and vintage year should be considered if we want to use the elemental composition for wine traceability.

Another study [5] proposes abstract liquid chromatography coupled to high-resolution mass spectrometry (LC-Q/TOF) to identify grape secondary metabolites that can potentially be used as chemical markers for the traceability of corresponding wines. In this experience the profiles of flavonols, flavanols and flavanones, glycoside terpenols, procyanidins, stilbenes, and anthocyanins of four Italian varieties (Corvina, Raboso Piave, Primitivo, and Negro Amaro) were determined, and the peculiar metabolites-the possible traceability markers of the corresponding wines-were identified. The authors suggest that this approach can successfully be used for the traceability of other wines.

Other chemical markers can be considered for wine traceability, in particular, isotope ratios of bio-elements $(13 \mathrm{C} / 12 \mathrm{C}, \mathrm{D} / \mathrm{H}, 18 \mathrm{O} / 16 \mathrm{O})$ or radiogenic heavy elements like $87 \mathrm{Sr} / 86 \mathrm{Sr}$, which were studied in the Chianti Classico production area [6]. This study aimed to verify whether the Sr isotopic ratio coming from vine branches can be a more distinctive geographical traceability tool. The strontium isotope ratio data $(87 \mathrm{Sr} / 86 \mathrm{Sr}$ ) were acquired using a double-focusing multi-collector inductively coupled plasma mass spectrometer (MC-ICP/MS). The results showed that the $87 \mathrm{Sr} / 86 \mathrm{Sr}$ ratio is not influenced by soil particle size and may represent an effective tool as a geographic provenance indicator for the investigated product.

SNIF-NMR (Site Specific Natural Isotope Fractionation, Nuclear Magnetic Resonance) and IRMS (Isotopic Ratio Mass Spectroscopy) techniques are widely used to assess the geographical origin of food, beverages and wines. These instrumental analyses were applied by other researchers [7] in some Italian wines (Verdicchio, Fiano, Refosco dal Peduncolo Rosso and Nero d'Avola). The wine isotope results (13C/12C, D/H, 18O/16O ratios) were subjected to multivariate statistical analysis, such as principal component analysis (PCA), together with wine chemical and sensory parameters to characterize the vintage and identify the origin of some Italian wines produced from different varieties. Moreover, the results of the PCA on all the wine parameters (isotopes, chemical and sensory data) showed that it was also possible to discriminate wines of the same variety produced in regions with different soil and climatic conditions.

The last paper [8] focused on the role of rare earth elements (REEs) as geochemical markers in wine traceability analyzing soil, grapes, musts, and wine samples of an Italian red wine (Primitivo di Manduria) using ICP-MS. The authors considered REE distributions in samples taken at each step of the wine production process and showed that the original distribution in soil remains unaltered in every intermediate product up to and including the grape must. Variation of REE composition can be caused by additives used to promote fermentation or by the interaction with the surfaces of storage tanks.

Acknowledgments: All the authors who kindly contributed with their experience and knowledge to this Special Issue are gratefully acknowledged. All my thanks to MDPI for the opportunity to be guest editor of this Special Number.

Conflicts of Interest: The authors declare no conflicts of interest.

\section{References}

1. Palade, L.; Popa, M. Polyphenol Fingerprinting Approaches in Wine Traceability and Authenticity: Assessment and Implications of Red Wines. Beverages 2018, 4, 75. [CrossRef]

2. Pereira, L.; Gomes, S.; Barrias, S.; Preto Gomes, E.; Margarida Baleiras-Couto, M.; Fernandes, J.R.; Martins-Lopes, P. From the Field to the Bottle-An Integrated Strategy for Wine Authenticity. Beverages 2018, 4, 71. [CrossRef]

3. Costa, N.L.; García Llobodanin, L.A.; Alves Castro, I.; Barbosa, R. Geographical classification of Tannat wines based on support vector machines and feature selection. Beverages 2018, 4, 97. [CrossRef]

4. Catarino, S.; Madeira, M.; Monteiro, F.; Caldeira, I.; Bruno de Sousa, R.; Curvelo-Garcia, A. Mineral Composition through Soil-Wine System of Portuguese Vineyards and Its Potential for Wine Traceability. Beverages 2018, 4, 85. [CrossRef] 
5. Mayr, C.M.; De Rosso, M.; Dalla Vedova, A.; Flamini, R. High-Resolution mass spectrometry identification of secondary metabolites in four red grape varieties potentially useful as traceability markers of wines. Beverages 2018, 4, 74. [CrossRef]

6. Sighinolfi, S.; Durante, C.; Lisa, L.; Tassi, L.; Marchetti, A. Influence of Chemical and Physical Variables on 87Sr/86Sr Isotope Ratios Determination for Geographical Traceability Studies in the Oenological Food Chain. Beverages 2018, 4, 55. [CrossRef]

7. Bonello, F.; Cravero, M.C.; Dell'Oro, V.; Tsolakis, C.; Ciambotti, A. Wine Traceability Using Chemical Analysis, Isotopic Parameters, and Sensory Profiles. Beverages 2018, 4, 54. [CrossRef]

8. Aceto, M.; Bonello, F.; Musso, D.; Tsolakis, C.; Cassino, C.; Osella, D. Wine traceability with rare earth elements. Beverages 2018, 4, 23. [CrossRef]

(C) 2019 by the author. Licensee MDPI, Basel, Switzerland. This article is an open access article distributed under the terms and conditions of the Creative Commons Attribution (CC BY) license (http://creativecommons.org/licenses/by/4.0/). 